\title{
Spinal epidural angiolipoma: a case report on sudden hemorrhagic onset and review of the literature
}

\author{
Chang Ho Lee, Dong Wuk Son, Su Hun Lee, Jun Seok Lee, Sang Weon Lee, Geun Sung Song \\ Department of Neurosurgery, Research Institute for Convergence of Biomedical Science and Technology, Pusan National University Yangsan Hospital, Pusan National \\ University School of Medicine Yangsan, Korea
}

Spinal epidural angiolipoma is an uncommon benign tumor composed of vascular and fat elements. Hemorrhagic transformation of angiolipoma is very rare, and only a few cases have been reported. Herein, we report a very rare case of the surgical removal of an angiolipoma that had undergone hemorrhagic transformation. On preoperative radiological studies, it was difficult to differentiate between a simple hematoma and a mass. Dynamic contrast-enhanced magnetic resonance imaging confirmed the presence of a hypervascular mass and total en bloc removal was planned. The patient underwent T3-5 laminectomy and tumor removal surgery, and his symptoms gradually improved.

Keywords: Angiolipoma; Epidural neoplasms; Spinal cord neoplasms

\section{Introduction}

Spinal angiolipoma is composed of adipocyte and abnormal vascular elements [1]. It has an incidence of $0.04 \%$ to $1.2 \%$ among all spinal axis tumors and $2 \%$ to $3 \%$ among extradural spinal tumors [2]. Most spinal angiolipoma are expressed at the thoracic level and are associated with signs of cord compression as they enlarge slowly, therefore, a sudden deterioration in symptoms does not occur. However, hemorrhagic transformation of angiolipoma, although rare, may cause sudden worsening of neurological symptoms [3-5]. Unfortunately, it is difficult to differentiate these cases from simple hematoma. Herein, we report a case of hemorrhagic transformation of angiolipoma, in which we used dynamic contrast-enhanced magnetic resonance imaging (DCE-MRI) for the preoperative discrimination between the tumor and hematoma, and our surgical experience.

Received: February 9, 2021

Revised: March 12, 2021

Accepted: March 26, 2021

Corresponding author: Dong Wuk Son, MD, PhD

Department of Neurosurgery, Pusan National University Yangsan Hospital, 20 Geumo-ro, Mulgeum-eup, Yangsan 50612, Korea

Tel: +82-55-360-2126; Fax: +82-55-360-2156; E-mail: md6576@naver.com

\section{Case Report}

A 60-year-old male suffering from back pain radiating to lower extremities bilaterally and gait disturbance for the past 6 months visited our out-patient department. Physical examination revealed hypoesthesia, decreased perception of pain, temperature, and fine touch below the level of T6, and difficulty in voiding. Muscle strength was $5 / 5$ according to the medical research council grading system in all the muscle groups. He had a normal body mass index (BMI), and past clinical and family history were unremarkable.

Sagittal T1-weighted MRI showed a lenticular-shaped mass, 5.7 $\mathrm{cm}$ in size, at the T3-T5 posterior epidural space with heterogeneous iso-intensity to low-intensity relative to the spinal cord (Fig. 1A). Sagittal T2-weighted MRI showed a high-intensity lesion (Fig. 1B), whereas sagittal T1 post-contrast MRI showed persistent hyperenhancement (Fig. 1C). Based on these findings, epidural hematoma was first suspected. DCE-MRI was performed afterwards, and its findings pointed toward the presence of a meningioma or angiolipoma.

Total surgical resection of the mass was planned. We performed total laminectomy at the level of $\mathrm{T} 3$ to $\mathrm{T} 5$ with gross total resection. A large firm highly vascular yellowish-brown mass receiving blood supply from many epidural vessels was found with a small hematoma at the T3-T5 posterior epidural space. The yellowish 

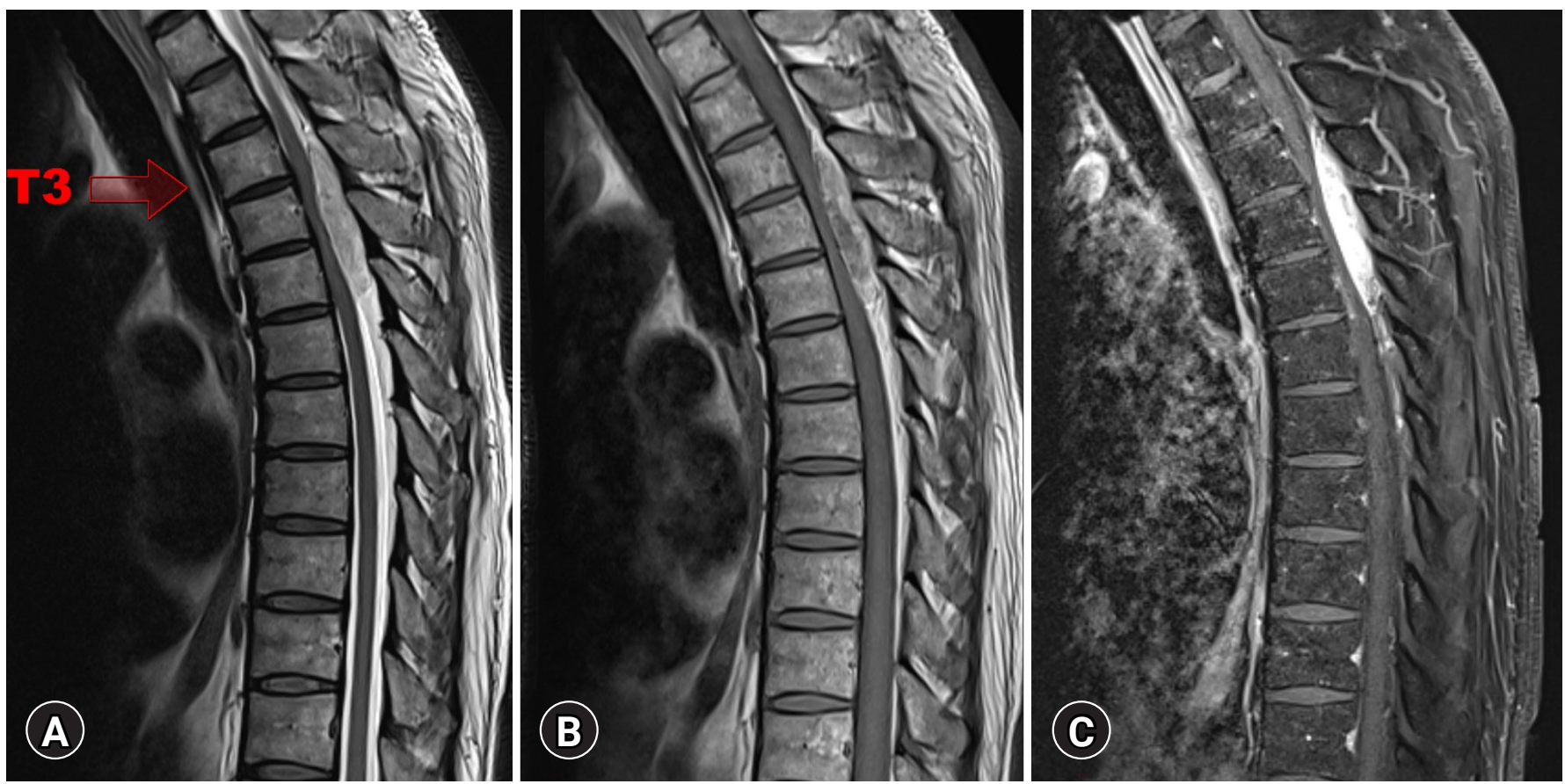

Fig. 1. Magnetic resonance imaging (MRI). (A) A sagittal T1-weighted MRI image shows a 5.7-cm, lenticular-shaped mass lesion in the posterior epidural space at the T3-T5 level with heterogeneous iso-intensity and low-intensity compared with the spinal cord. (B) Sagittal T2-weighted MRI shows a high signal intensity. (C) Sagittal T1 post-contrast MRI shows persistent hyperenhancement.

fat layer was clearly demarcated from the dura. The epidural vessels appeared to arise from the lateral side. During tumor resection, a large amount of bleeding occurred; therefore, piecemeal removal was performed. In addition, no infiltration of bone or surrounding tissues was observed (Fig. 2). Neurophysiological monitoring was performed during the operation and no specific findings were seen. Pathological analysis of frozen biopsy measuring $1.4 \times 1.0 \mathrm{~cm}$ in size showed mature and immature fatty tissue measuring $1.4 \mathrm{~g}$ in weight, whereas analysis of the biopsy measuring $2.6 \times 2.1 \times 0.3$ $\mathrm{cm}$ in size revealed the presence of fat and capillary-sized vessels, which confirmed the diagnosis of angiolipoma (Fig. 3).

The patient's symptoms improved after the operation. However, antibiotics were administered for 16 days due to high C-reactive protein (CRP) levels and the patient was discharged after the discontinuation of antibiotics when the CRP level returned to normal. Three months after the operation, MRI follow-up was performed and there was no recurrence (Fig. 4).

This study was approved by the Institutional Review Board of Pusan National University Yangsan Hospital (IRB No: 05-2021110). Written informed consent by the patients was waived due to a retrospective nature of our study.

\section{Discussion}

The basic etiology of angiolipoma has not been elucidated yet [6].

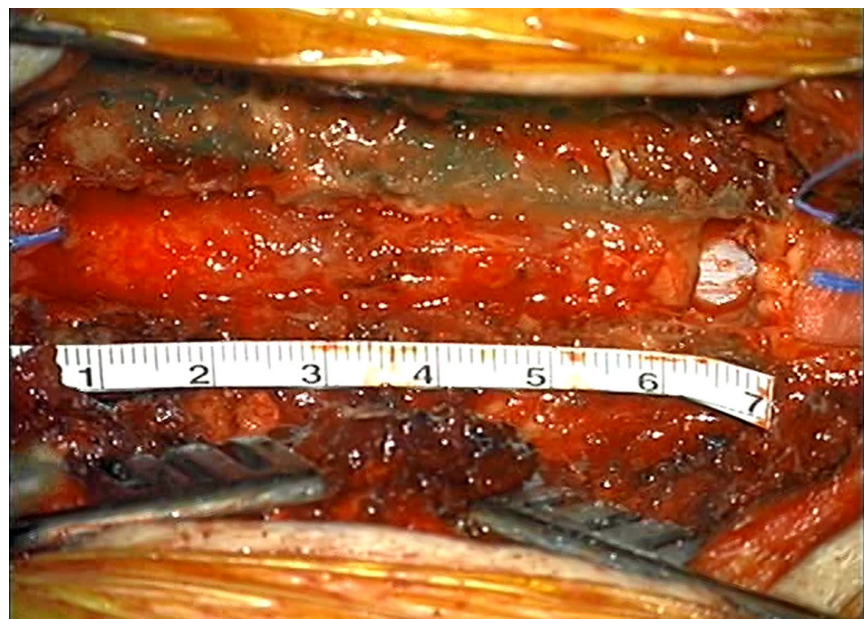

Fig. 2. Intraoperative tumor image. Total laminectomy was performed from T3 to T5. We found a huge $(6 \mathrm{~cm})$ and firm yellowish-brown mass that covered numerous epidural vessels, with a small hematoma in the posterior epidural area from T3 to T5.

It is a disease that mainly occurs in the subcutaneous tissue of the trunk and limbs. It rarely involves the spinal cord, and occurs mainly on the dorsal aspect of the thoracic levels. However, some studies have suggested that angiolipoma develops as a result of pluripotent mesenchymal stem cells with secretory activity, and malignant transformation and involvement of neural tissue has not yet been 


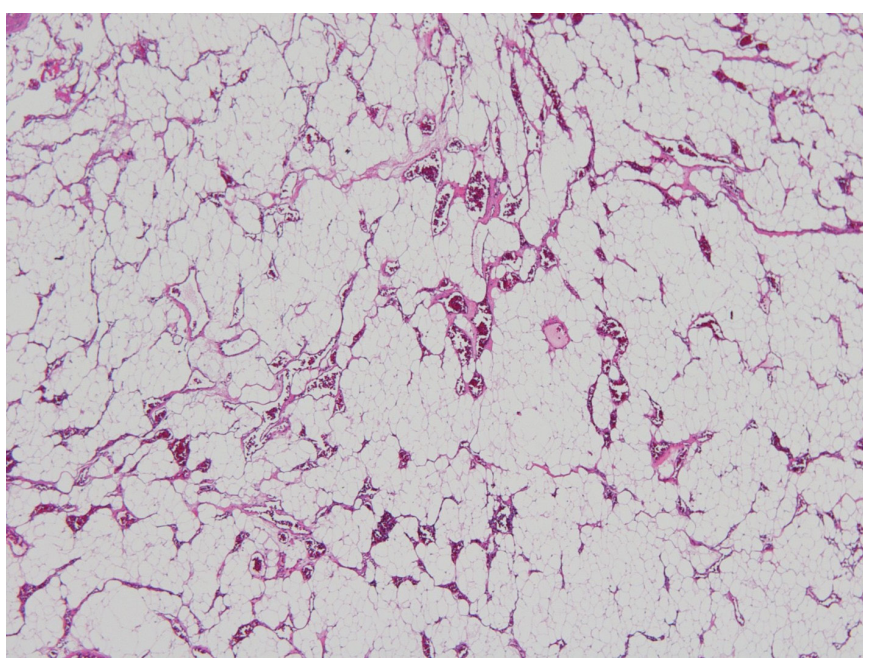

Fig. 3. Pathologic examination. Biopsy-obtained permanent tissue specimen weighing $1.4 \mathrm{~g}$ and measuring $2.6 \times 2.1 \times 0.3 \mathrm{~cm}$, consisting of fat and capillary-sized vessels. The mass was diagnosed as an angiolipoma $\left(H \& E_{1} \times 100\right)$.

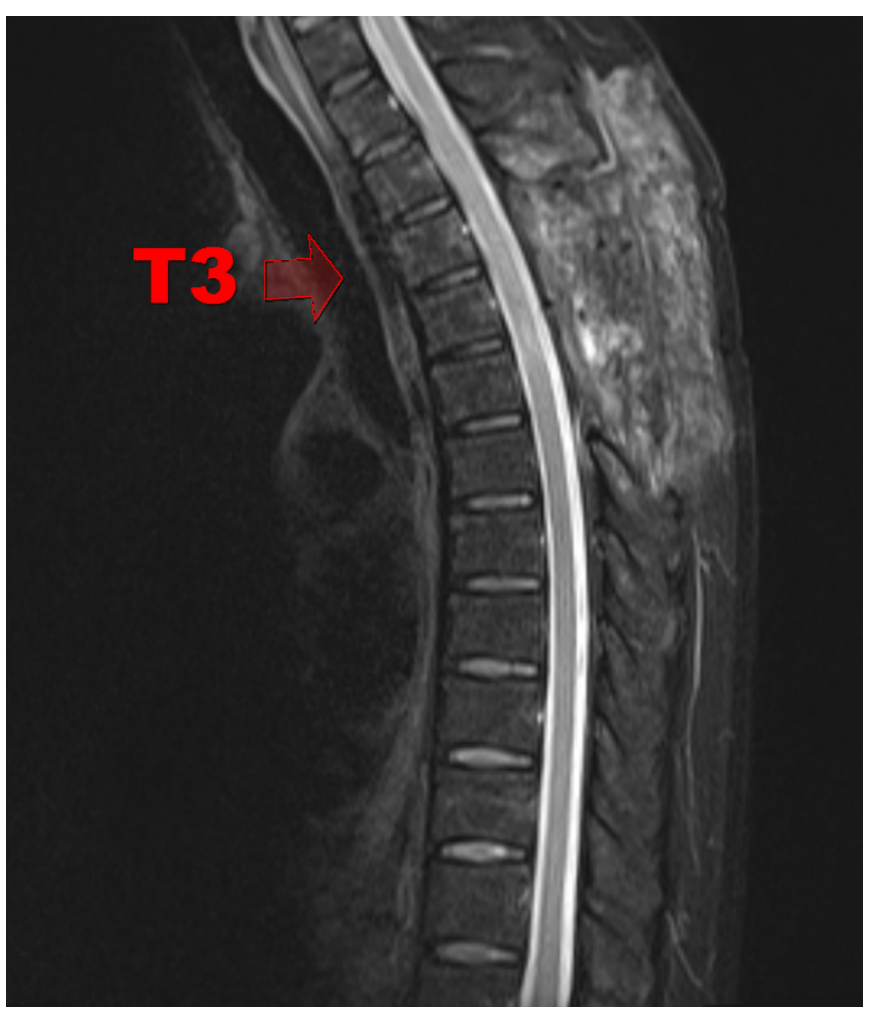

Fig. 4. Follow-up magnetic resonance imaging. Three months later, follow-up was performed and there was no recurrence.

reported [7]. Angiolipoma occurs predominantly in women and obese people, and is more likely to be observed in pregnant women with sudden weight gain [8]. Pregnancy interferes with spinal venous drainage and increases epidural venous pressure. In addition, adiposity increases due to the hormonal effects of pregnancy, which may lead to the proliferation of angiolipoma [9].

Extradural spinal angiolipoma was first observed on autopsy in 1890. Pathological reports were first published by Howard in 1960 [7].

Pathological features include fat and vessels in a ratio of $1: 3$ to $2: 3$ and consist of mature fat cells, and abnormal capillary, sinusoidal, venous, or arterial vascular tissues [10]. Pathologically, lesions with copious smooth muscle proliferation are subclassified as angiomyolipoma [11]. The tumor resected in the present case was composed of adipocyte and capillary-sized vessels. It was not significantly different from other angiolipomas (Fig. 3).

Plain radiography is the most basic investigation that can be performed initially; but its ability to detect the tumors is limited. However, infiltrating tumors may show erosion of the pedicle, widening of the spinal canal, and trabeculation of the vertebral body on X-ray $[11,12]$. There was no abnormal X-ray finding in the present case.

On computed tomography (CT), spinal angiolipoma generally shows low or intermediate-density. On contrast-enhanced CT, angiolipoma appears hypodense, whereas some tumors have an isodense appearance, which is related to the rich and extensive vascularity [13]. In this case, CT scan showed a lenticular shaped mass with heterogeneous isodensity at $\mathrm{T} 3-\mathrm{T} 5$ posterior epidural space.

MRI is the gold standard for the diagnosis of spinal angiolipoma [14]. Spinal angiolipoma usually appears homogenous and hypointense on T1-weighted images due to the fat content. On T2-weighted images, it can show a variable pattern, but it is mostly hyperintense. In this case, heterogeneous, iso and low-intensity signals were seen on MRI T1-weighted images and heterogeneous and high-intensity signals were seen on T2-weighted images. Therefore, hematoma was suspected. An additional investigation (DCE-MRI) was also performed. Gadolinium is injected in DCEMRI to obtain vascularization and perfusion data by analyzing the tissue changes. This is useful for the diagnosis and treatment of the brain and breast tumors. When DCE-MRI of the spine is performed, the vascularity, perfusion, and capillary permeability of the tumor can be analyzed $[15,16]$. In this case, DCE-MRI showed high vascularity with early and persistent hyperenhancement of the tumor (Fig. 5). Angiography can also be used for the diagnosis and treatment of some spinal angiolipomas. Resection of a highly vascularized spinal angiolipoma that appears hypointense on the T1-weighted images may be facilitated by embolization before surgery [10].

Symptoms of spinal angiolipoma vary according to the tumor location and its compression of the surrounding structures. Most sensory and motor deficits occur below the level of the lesion, 

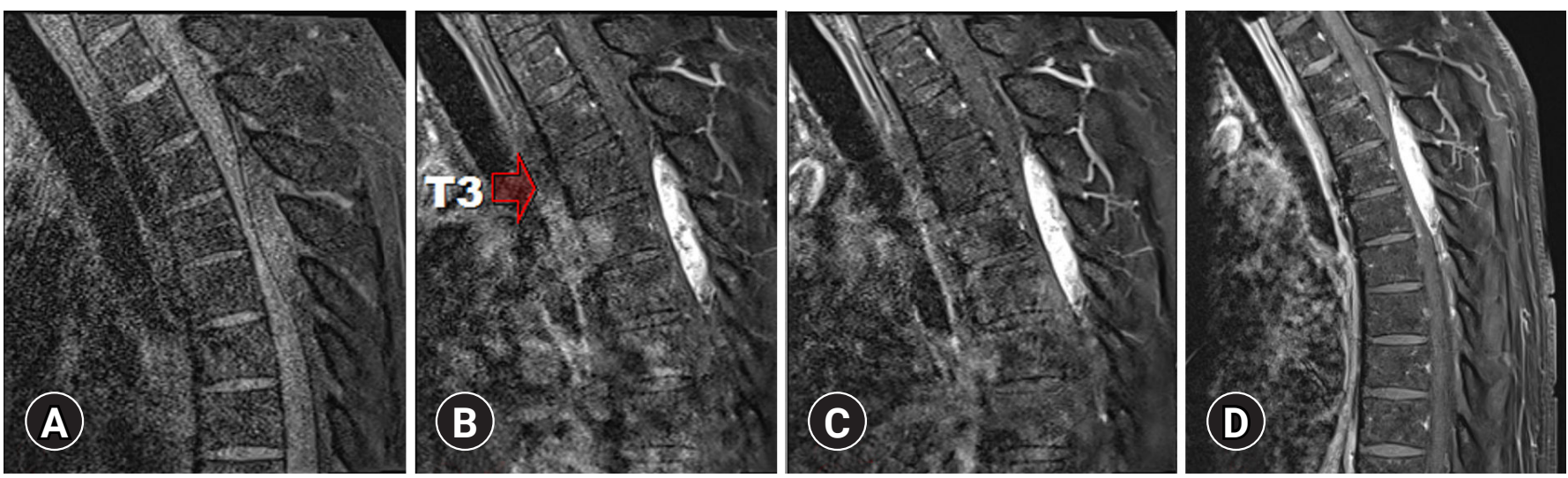

Fig. 5. Dynamic contrast-enhanced magnetic resonance imaging (MRI). (A) Non-contrast MRI scan. (B) Thirty seconds after contrast injection, an early-enhancing tumor (arrow) lesion is seen. (C) Sixty seconds after the contrast injection, more enhancement of the tumor lesion is observed. (D) Contrast MRI scan.

which is similar to the symptoms of spinal cord compression. Spinal angiolipoma is characterized by slow progression, enlarging gradually over months, with diagnoses occurring within a year $[17,18]$. The occurrence of symptoms may be due to poor vascular drainage, which may lead to engorgement, enlargement or degeneration of the blood vessels. The occurrence of steal phenomenon, venous thrombosis, and hemorrhage can contribute to the development or sudden worsening of the symptoms $[17,19,20]$. Only a few cases have been reported in which hemorrhagic transformation of angiolipoma was accompanied by the sudden exacerbation of the neurological symptoms. Akhaddar et al. [3] reported the first such case in 2008. This was a case of a 47-year-old male who developed sudden paresthesia and complete neurological palsy within a few minutes due to the hemorrhagic epidural angiolipoma. In 2018 Horiuchi et al. [4] reported the case of a 49-yearold female with obesity (BMI, $31.1 \mathrm{~kg} / \mathrm{m}^{2}$ ) who presented with a 1-week history of progressively worsening back pain, paresthesia of the lower limbs, and gait disturbance. Surgery was performed and angiolipoma was diagnosed on the pathological examination after surgery. In 2020, an unusual case was reported in angiolipoma underwent hemorrhagic transformation due to a traumatic factor (back massage) [5]. In this case, DCE-MRI was used to make the diagnosis of a mass, rather than simple hematoma, before surgery. The diagnosis of a tumor should not be missed because of the presence of hemorrhage. DCE-MRI before and pathological analysis during surgery must be performed for the diagnosis.

Spinal angiolipoma is classified into two types, non-infiltrating and infiltrating. The non-infiltrating type is more common and exhibits encapsulation. However, the infiltrating type has indefinite boundaries, is mainly unencapsulated, has sporadic features, and occasionally shows infiltration of the bone and surrounding tissues. Although there is some difference in the treatment plan, sur- gical resection is the gold standard regardless of the type. Total tumor resection is the treatment of choice, but it may be difficult to achieve for the infiltrating type. Even with subtotal removal, most patients show good results. This is due to the nature of the tumor, because it does not undergo malignant transformation and is slow-growing. In addition, in the case of recurrent tumor as reported by Gonzalez-Crussi et al. [13], combined treatment with radiotherapy and surgery may be performed. In case of highly vascularized spinal angiolipoma, embolization is performed before attempting surgical removal [10].

The mean age of incidence of spinal angiolipoma is 42.9 years (range, 10 days- 85 years). The incidence of spinal angiolipoma is expected to increase in the aging societies. Comorbid conditions need to be considered before performing surgery in elderly patients. However, spinal angiolipoma surgery has good outcomes. Even though, caution should be exercised in the treatment of elderly patients with spinal angiolipoma, surgical resection remains the recommended treatment for these patients.

\section{Conclusion}

The process of diagnosing spinal angiolipoma is long because of the nature of the tumor. Until now, routine CT and MRI imaging studies had been performed for the diagnosis. In this case, DCEMRI was performed to enable differentiation of angiolipoma from other spinal neoplasms as well as simple hematoma, and to evaluate the vascularity of the tumor. These assessments have a positive impact on the planning of the surgery. We performed total resection of the tumor with subsequent improvement in the patient's neurological symptoms and no recurrence on follow-up. 


\section{Conflicts of interest}

No potential conflict of interest relevant to this article was reported.

\section{ORCID}

Chang Ho Lee, https://orcid.org/0000-0002-0356-5731

Dong Wuk Son, https://orcid.org/0000-0002-9154-1923

Su Hun Lee, https://orcid.org/0000-0001-8952-5556

Jun Seok Lee, https://orcid.org/0000-0003-2488-6953

Sang Weon Lee, https://orcid.org/0000-0002-3199-7072

Geun Sung Song, https://orcid.org/0000-0001-8029-9011

\section{REFERENCES}

1. Gelabert-González M, García-Allut A. Spinal extradural angiolipoma: report of two cases and review of the literature. Eur Spine J 2009; 18:324-35.

2. Si Y, Wang Z, Pan Y, Lin G, Yu T. Spinal angiolipoma: etiology, imaging findings, classification, treatment, and prognosis. Eur Spine J 2014;23:417-25.

3. Akhaddar A, Albouzidi A, Elmostarchid B, Gazzaz M, Boucetta M. Sudden onset of paraplegia caused by hemorrhagic spinal epidural angiolipoma: a case report. Eur Spine J 2008;17(Suppl 2):S296-8.

4. Horiuchi K, Yamada T, Sakai K, Okawa A, Arai Y. Hemorrhagic sudden onset of spinal epidural angiolipoma. Case Rep Orthop 2018;2018:5231931.

5. Zhang X, Wang JJ, Guo Y, et al. Sudden aggravated radicular pain caused by hemorrhagic spinal angiolipomas after back massage. World Neurosurg 2020;134:383-7.

6. Yang X, Richard SA, Lei C, Liu J, Huang S. Spinal extradural angiolipoma: a report of two cases and review of literature. J Spine Surg 2018;4:490-5.

7. Onishi FJ, Salem FAS, de Melo Lins DL, Dauar RF, Stavale JN. Spinal thoracic extradural angiolipoma manifesting as acute onset of paraparesis: case report and review of literature. Surg Neurol Int 2017;8:150.
8. Hungs M, Paré LS. Spinal angiolipoma: case report and literature review.J Spinal Cord Med 2008;31:315-8.

9. Balado M, Morea R. Extramedular haemangioma producing paraplegia during pregnancy. Arch Argent Neurol 1928;1:34551.

10. Lin JJ, Lin F. Two entities in angiolipoma. A study of 459 cases of lipoma with review of literature on infiltrating angiolipoma. Cancer 1974;34:720-7.

11. Guzey FK, Bas NS, Ozkan N, Karabulut C, Bas SC, Turgut H. Lumbar extradural infiltrating angiolipoma: a case report and review of 17 previously reported cases with infiltrating spinal angiolipomas. Spine J 2007;7:739-44.

12. Mascalchi M, Arnetoli G, Dal Pozzo G, Canavero S, Pagni CA. Spinal epidural angiolipoma: MR findings. AJNR Am J Neuroradiol 1991;12:744-5.

13. Gonzalez-Crussi F, Enneking WF, Arean VM. Infiltrating angiolipoma. J Bone Joint Surg Am 1966;48:1111-24.

14. Konya D, Ozgen S, Kurtkaya O, Pamir NM. Lumbar spinal angiolipoma: case report and review of the literature. Eur Spine J 2006;15:1025-8.

15. Khadem NR, Karimi S, Peck KK, et al. Characterizing hypervascular and hypovascular metastases and normal bone marrow of the spine using dynamic contrast-enhanced MR imaging. AJNR Am J Neuroradiol 2012;33:2178-85.

16. Fayad LM, Jacobs MA, Wang X, Carrino JA, Bluemke DA. Musculoskeletal tumors: how to use anatomic, functional, and metabolic MR techniques. Radiology 2012;265:340-56.

17. Andaluz N, Balko G, Bui H, Zuccarello M. Angiolipomas of the central nervous system. J Neurooncol 2000;49:219-30.

18. Preul MC, Leblanc R, Tampieri D, Robitaille Y, Pokrupa R. Spinal angiolipomas. Report of three cases. J Neurosurg 1993;78: 280-6.

19. Boockvar JA, Black K, Malik S, Stanek A, Tracey KJ. Subacute paraparesis induced by venous thrombosis of a spinal angiolipoma: a case report. Spine (Phila Pa 1976) 1997;22:2304-8.

20. Oge HK, Soylemezoglu F, Rousan N, Ozcan OE. Spinal angiolipoma: case report and review of literature. J Spinal Disord 1999; $12: 353-6$. 